\title{
Studying the effect of drying technology on silk cocoon shell and chrysalis features
}

\author{
Azamat Gulamov ${ }^{1}$, Komil Avazov ${ }^{1 *}$, and Bekzod Abrayqulov ${ }^{1}$ \\ ${ }^{1}$ Tashkent Institute of Textile and Light Industry, 100100 Tashkent, Uzbekistan
}

\begin{abstract}
This article proposes the influence of the cocoon drying technology on the properties of the shell and pupa of the silkworm. We also analyzed the change in the initial weight of the cocoons treated at different temperatures, the microscopic view of the cocoon shells. Cocoons grown at different times of the year were taken as the object of the study. As a result of the treatment of the cocoon pupa with an infrared ray, hot air and chemical methods, the yield, color properties and solubility of the cocoon shell were compared and analyzed.
\end{abstract}

\section{Introduction}

The Republic of Uzbekistan has adopted a law on family business and a number of decrees and resolutions of the President of the Republic of Uzbekistan. On March 16, 2012, the Law "On Family Business" was adopted. On January 5, 2006, the President signed a decree "On measures to encourage the expansion of cooperation between large industrial enterprises and the development of home-based production and services." The development of family business, increasing the number of services provided to them is becoming a vital necessity for our country [1].

The main raw materials of the textile industry of the republic are cotton fiber, cocoons and raw silk. In the eighties of the last century in our country $1.5 \mathrm{mln}$ tons of cotton fiber, 32,000 tons of wet cocoons and 2,500 tons of raw silk. While only 5-6\% of cotton fiber is processed in textile enterprises, the remaining fiber is exported as a raw material. Raw silk is fully processed to produce national fabrics and classic crepe fabrics. At the same time, it should be noted that the production of ready-made garments from local fabrics, especially knitwear, is not organized at the required level, the lack of enterprise capacity, modern equipment, the introduction of scientific innovations, the lack of legal guarantees in stateowned enterprises [2-5].

The Association of Textile Industry received exported finished products, they have a significant contribution to the structure of the cotton-weaving cluster. The establishment of a new cluster structure in the industry is developing. The formation of the Uzbekpaksanoat Association in accordance with the decrees of the President in 2017 led to the beginning of radical changes in silk production and silk processing. Significant work is being done to establish mulberry groves, develop seed production, increase the number of silkworm

\footnotetext{
*Corresponding author: komil.avazov@mail.ru
} 
rearing to four in the spring and summer months, and transfer cocoon cultivation to the industrial method [6-9].

\section{Materials and Methods}

The fungus inside the cocoons taken to the preparation points is alive. In order for cocoon mills to operate continuously throughout the year, it is necessary to anesthetize and dry the cocoon so that the cocoon can be stored throughout the year [10-12].

Otherwise, a live sponge can turn into a butterfly, pierce the shell, render the cocoon unfit for rinsing, or if it is anesthetized and not dried, the wet cocoon will quickly mold and the cocoon will be of poor quality. Therefore, raw silk is produced continuously throughout the year from the cocoons until the new year season cocoons are delivered to the cocoon mills [13]. Anesthetizing a live cocoon, reducing the high amount of moisture in it, is the process of pre-processing the cocoons. In carrying out this process, it is necessary to maintain a high level of physicochemical properties of fibroin and sericin in the cocoon shell, and the natural technological and physico-mechanical properties of cocoon yarn [14].

The cocoon strip consists of protein compounds - fibrion and sericin, whose molecule consists of a chain of high numbers of amino acids. The molecular length gives natural silk high elasticity and flexibility. Fibroin is resistant to enzymes, insoluble in alcohol, ether and other solutions, resistant to weak acids, swells in water, but does not change its structure $[15,16]$.

\section{Results}

Since sericin, which binds the two fibrion threads, is also a protein, its physical, mechanical and chemical properties depend on the drying mode and storage conditions of the cocoons. Sericin begins to dissolve in water at a temperature of about $70{ }^{\circ} \mathrm{C}$, soluble in acid and base solutions. Due to its resistance to certain enzymes, it can be broken down by microorganisms. The water absorption and solubility of sericin have a significant effect on the washing of cocoons [12]. These technological parameters depend on the initial processing of them.

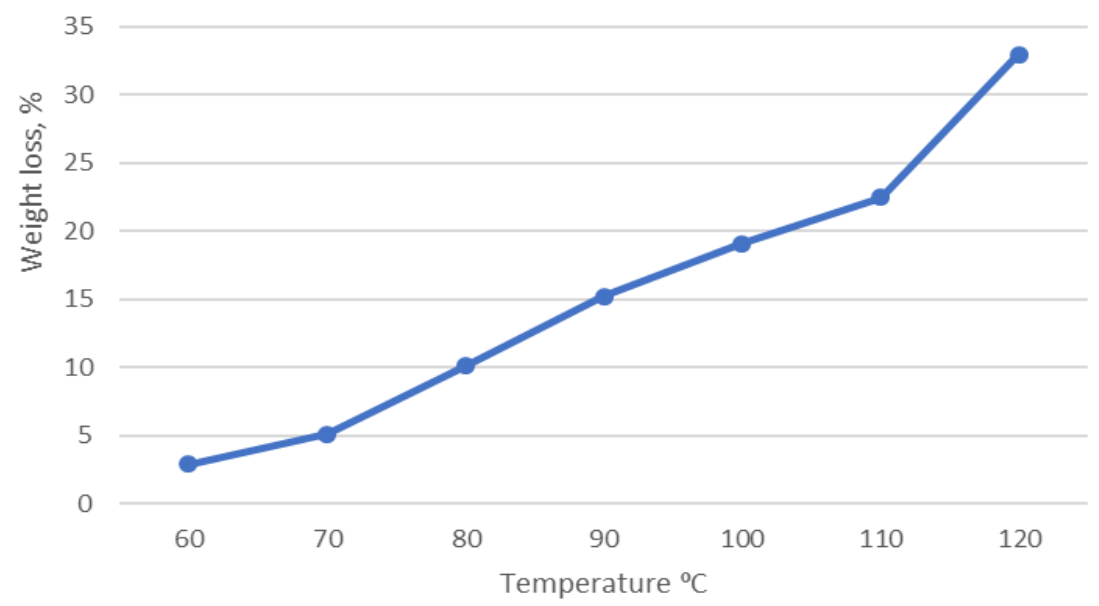

Fig. 1. Graph of weight loss as a result of processing cocoons at different temperatures for 60 minutes, \% 
Table 1. Microscopic view of the shell of cocoons processed at different temperatures

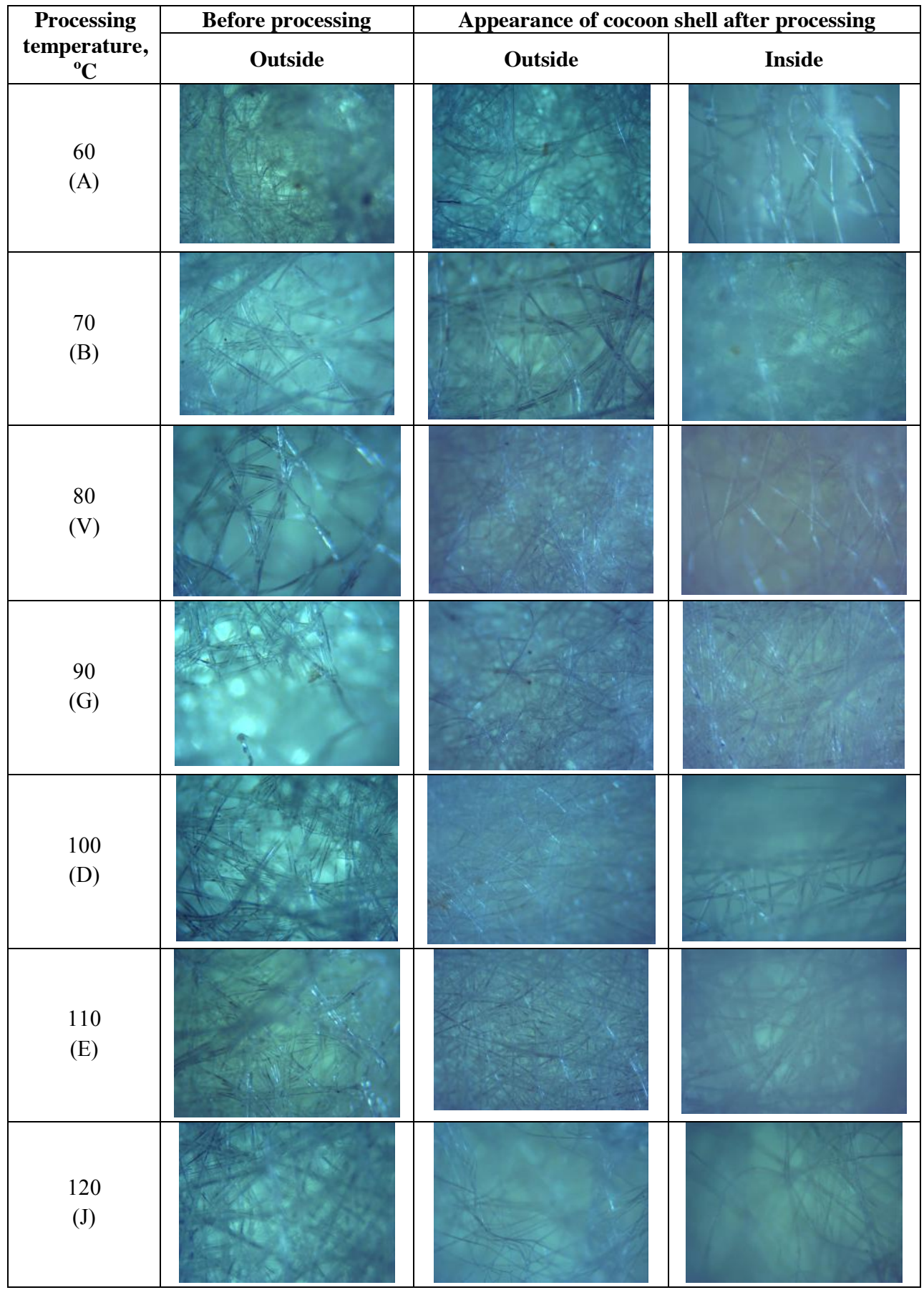

In order to test this method in practice and determine their technological regimes in the 2016-2020 cocoon production season, scientific research was conducted on the basis of "Silver fiber" LLC in Samarkand region, "Koson Agropilla" LLC in Kashkadarya region and Ortachirchik silkworm enterprises in Tashkent region and the department of "Silk 
Technology". To do this, their weight change was analyzed by treating the cocoons in hot air at different temperatures. The results are shown in the graph below (Fig. 1).

As can be seen from Fig. 1, we can see an increase in weight loss with increasing temperature. However, the higher the temperature, the worse the properties of the shell can be. In order to verify the above, the microscopic appearance of the cocoon shell treated at different temperatures was analyzed. The results are given in the table below (Table 1).

To date, there are several methods of pre-treatment of cocoons, which can be divided into two groups depending on the technology of annealing and drying of live cocoon fungus separately or in parallel.

In the first group - live cocoon fungus is anesthetized only, so the fungal inanimate cocoons are dried in shaded racks. These include processing methods using steam, chemicals, sealing, gamma rays, and storage in a cold environment.

In the second group - the above processes are equal, that is, the live cocoon is dried with the anesthesia. These include sunlight, vacuum, high frequency (HF), hot air (convective) and infrared light.

Due to the structure of the cocoon, the shell and the air space inside it, as well as the foam, undergoes a number of resistances until the high-temperature hot air supplied to it affects the sponge. The resulting hot air takes a long time and high temperature to deactivate the sponge and evaporate the liquid inside. This leads to changes in the natural properties of the cocoon shell and the sponge [8-15].

According to the results of preliminary scientific research, the optimal variants for anesthetizing a live cocoon sponge under the influence of infrared light have been identified. Based on the results of the study and the literature analysis, a method was proposed to anesthetize the live cocoon sponge under the influence of infrared light and then dry it in a shade dryer until continuous conditioned humidity [16].

The research was carried out on the existing SK-150K unit and the newly created live cocoon fungus anesthesia devices under the influence of infrared light. For the experiment, $1000 \mathrm{~kg}$ of live cocoons grown on the same farm under the same conditions in the spring and repeat seasons were sampled and divided into equal amounts of control and experimental variants. The cocoon samples of the control variant were present in the SK$150 \mathrm{~K}$ unit in hot weather at $110{ }^{\circ} \mathrm{C}$, and the experimental cocoons were anesthetized and dried in the shade in a new device. During the drying of cocoon samples in both variants, the change in moisture content during processing was found (Fig. 2).

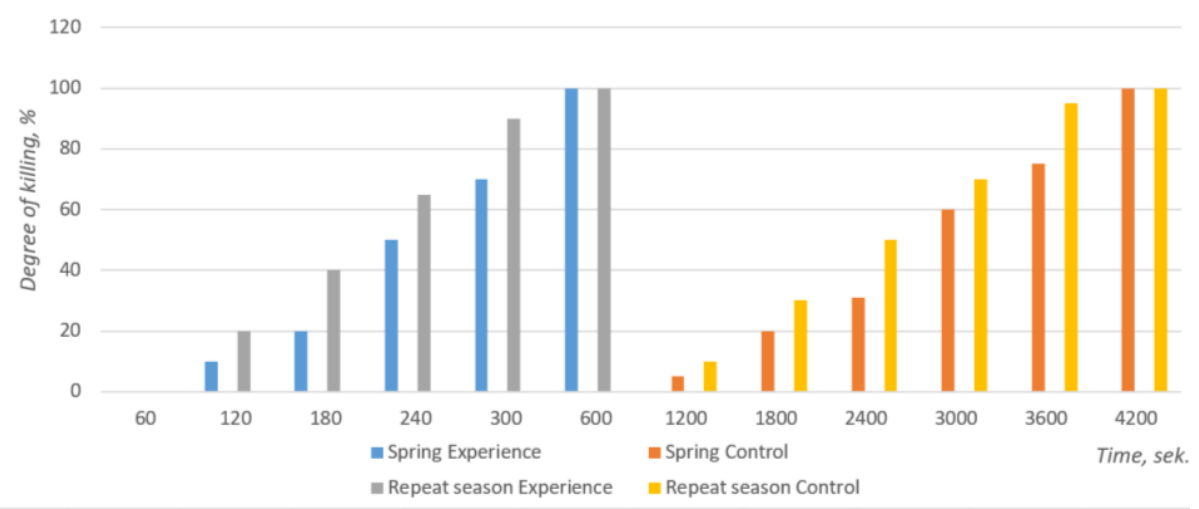

Fig. 2. Time dependence of anesthesia of live cocoon fungus under the influence of infrared light (experiment-left) and under the influence of hot air (control-right) 
As can be seen from Fig. 2, the time for complete anesthesia of the live cocoon sponge was 70 minutes in the control, and in the experiment it was found that 10 minutes would be sufficient for this. At the same time, cocoons grown in the replanting season showed that the cocoons die faster than in the spring, and this is not significantly different.

During the experiments, it was shown that their weight loss as a result of anesthesia of the cocoon fungus varied from $6.7 \%$ in the control and $0.5 \%$ in the experiment (Fig. 3).

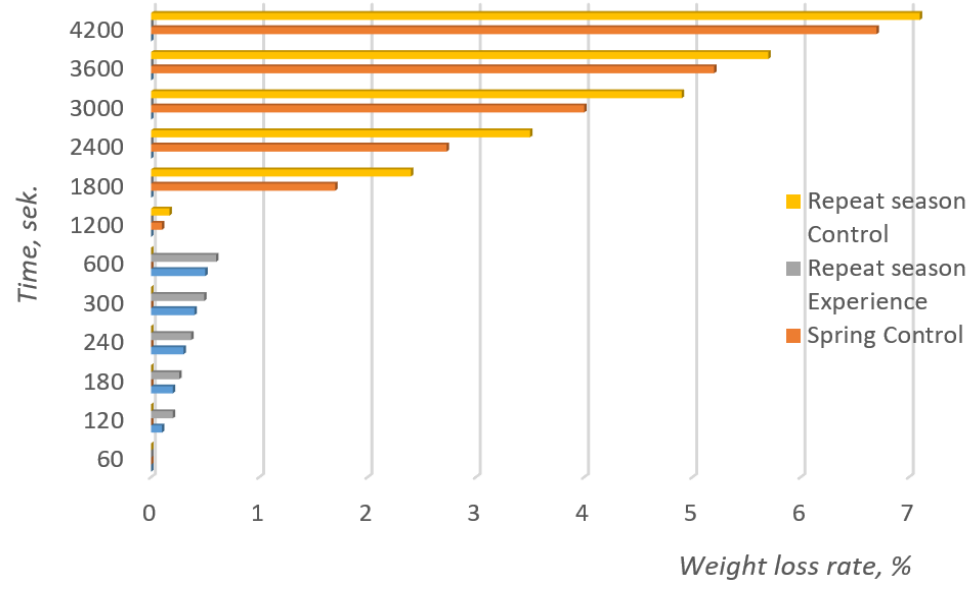

Fig. 3. Their weight change over the duration of killing of the cocoon chrysalis

During the study, 5 live cocoon samples of the same caliber, prepared in both seasons, were divided into three variants: the method available in Variant 1 in the drying unit SK$150 \mathrm{~K}$ at a temperature of $90{ }^{\circ} \mathrm{C}$ for 1.5 hours (partial drying of the chrysalis killing) and fully in the shade dryer. drying; In variant 2 , the live cocoon chrysalis is killing by fumigation with a chemical (Aluminum Phosphide 56\%) and completely dried in a shade dryer; In variant 3, the live cocoon chrysalis was anesthetized under infrared light and dried completely in a shade dryer [15]. As a result, some properties of the dry cocoon shell were identified.

Table 2. Output chrysalis of the cocoon and its effect on color.

\begin{tabular}{|c|c|c|c|c|c|c|}
\hline \multirow{2}{*}{ Variant } & \multirow{2}{*}{$\begin{array}{c}\text { Cocoon growing } \\
\text { season }\end{array}$} & \multirow{2}{*}{$\begin{array}{c}\text { Chrysalis } \\
\text { output } \\
(\%)\end{array}$} & \multicolumn{4}{|c|}{ Including color output, (\%) } \\
\hline & & & yellow & brown & black & worm \\
\hline \multirow{2}{*}{$\begin{array}{l}\text { 1-variant } \\
\text { (Hot air) }\end{array}$} & $\begin{array}{l}\text { Spring } \\
\text { (control) }\end{array}$ & 48,2 & 68,5 & 26,4 & 3,7 & 1,4 \\
\hline & $\begin{array}{l}\text { Repetition } \\
\text { (experiment) }\end{array}$ & 46,1 & 66,5 & 27,1 & 4,5 & 1,9 \\
\hline \multirow{2}{*}{$\begin{array}{c}\text { 2-variant } \\
\text { (Fumigation) }\end{array}$} & $\begin{array}{c}\text { Spring } \\
\text { (control) }\end{array}$ & 48,8 & 73,4 & 19,7 & 5,8 & 1,1 \\
\hline & $\begin{array}{l}\text { Repetition } \\
\text { (experiment) }\end{array}$ & 46,3 & 75,1 & 19,3 & 4,1 & 1,5 \\
\hline \multirow{2}{*}{$\begin{array}{c}\text { 3-variant } \\
\text { (Infrared rays) }\end{array}$} & $\begin{array}{l}\text { Spring } \\
\text { (control) }\end{array}$ & 48,6 & 71,1 & 21,3 & 6,6 & 1,0 \\
\hline & $\begin{array}{l}\text { Repetition } \\
\text { (experiment) }\end{array}$ & 46,2 & 74,2 & 19,8 & 4,2 & 1,8 \\
\hline
\end{tabular}

Three- to five-day-old mushrooms harvested in season are yellow in color and odorless. During the drying process, an odor is created when the protein in the sponge is used as a 
result of fermentation. As a result of changes in the fat content of the sponge, it turns brown, and if held for a long time in the heat, it turns dark brown or black. As a result, the oil in the sponge begins to burn into wax, which is very difficult to dissolve. Taking into account the above, the effect of processing in different modes on the chrysalis yield and its color was determined (Table 2).

It was found that the method and mode of processing the cocoons affect the output of the yellow chrysalis. In particular, the yield of yellow chrysalis in variant 1 control was $68.5 \%$, while in variants 2 and 3 it was higher by $4.9 \%$ (abs.) And 2.6\% (abs.), respectively. The yield of yellow chrysalis in the 1 st variant experiment was $66.5 \%$, and in the 2 nd and 3rd variants it was higher by $8.6 \%$ (abs.) and $7.7 \%$ (abs.), respectively.

\section{Discussions}

It is known that the correct choice of drying mode of cocoons is explained by the effect of the drying process on the properties of sericin. The properties of sericin are expressed through solubility, swelling and adhesion strength, while the properties of fibroin are reflected in the structure in terms of viscosity, viscosity, solubility and infrared spectrum. The sericin in the shell of the dry cocoons holds the cocoon thread firmly in place in the solid state. A force of up to $1.52 \mathrm{sN}$ is required to separate this cocoon yarn from the shell. In continuous spinning of cocoons with high-speed force, the force required to separate the thread from the shell should not exceed $0.2 \mathrm{sN}$. This requires that the cocoon shell swell and that the solubility of sericin be at the required level [12].

The peculiarity of the molecular structure of sericin is that the solvent passes easily into sericin. The passage of water into the sericin causes it to swell, separate, and partially dissolve. The semi-dispersion of the sericin molecule causes it to melt even when the temperature does not reach a critical point. Its solubility depends on the breed of cocoon, feeding conditions, their initial treatment (killing and drying chrysalis of the cocoon) and evaporation regimes. The melting point of sericin is calculated by the following expression:

$$
P_{a}=\frac{m_{0}-m_{k}}{m_{0}} \cdot 100 \%
$$

where, $m_{k}$ - the weight of the cocoon shell after boiling and $m_{0}$ - the dry weight of the cocoon shell before boiling.

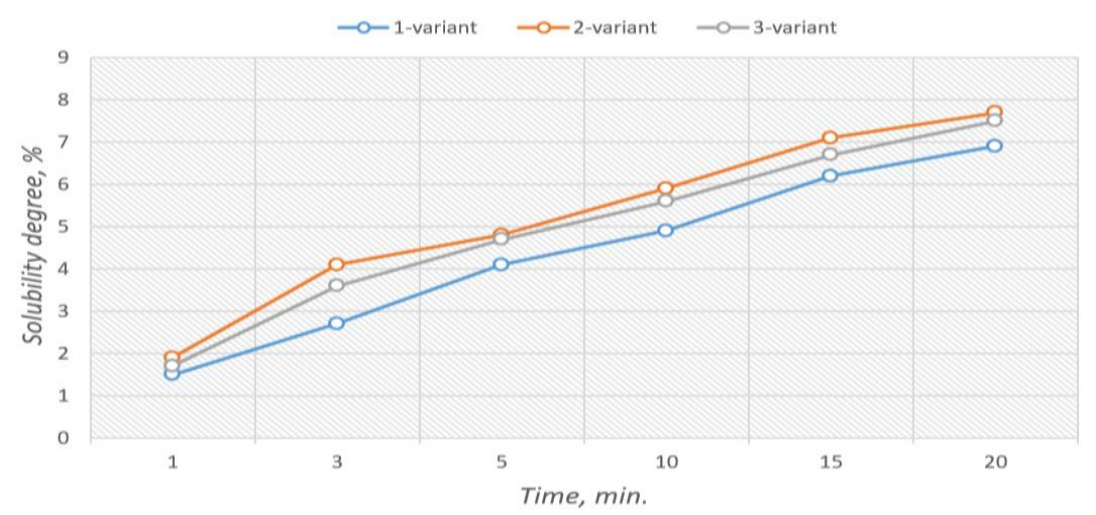

Fig. 4. Time dependence of the solubility of cocoon shells processed in different ways in the spring season (control) 


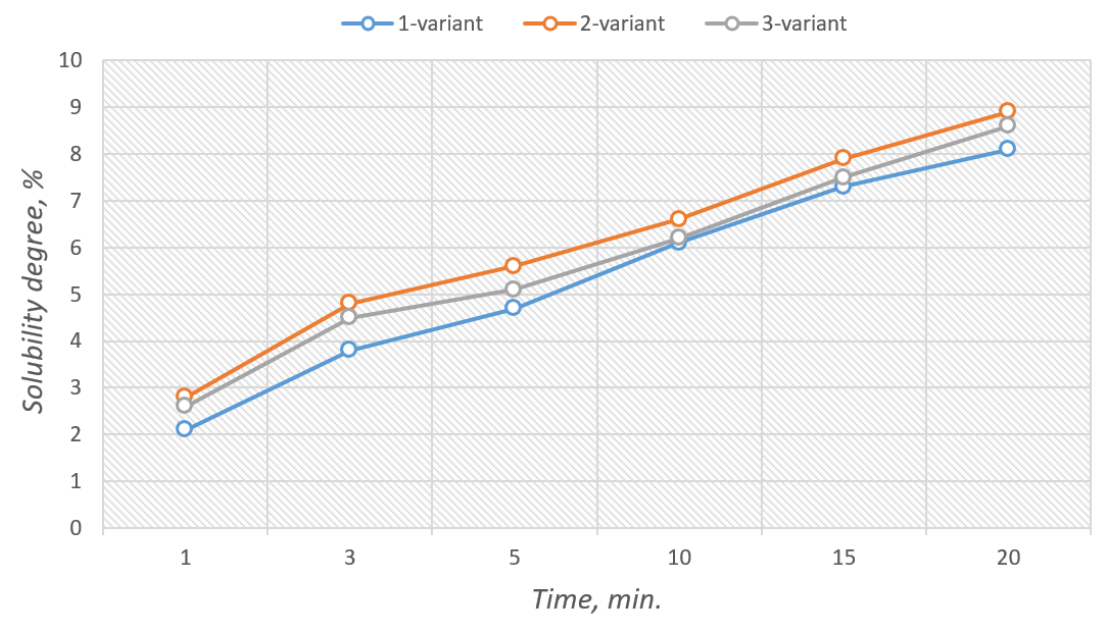

Fig. 5. Time dependence of the solubility of cocoon shells processed in different ways grown in the replanting season (experiment)

In order to test the solubility of sericin in the shells of cocoon samples grown in different spring and repeat seasons and processed in the above variants, 50 cocoon shell samples ( $i=10$ repetitions) were reduced by boiling them in distilled boiling water at different times according to the existing methodology. identified (Fig. 4 and 5).

The results of the study showed that the mode of drying the cocoon in hot weather affects the technological properties of the cocoon shell. The solubility of sericin in the cocoon shell treated in variant 1 was $0.97 \%$ (abs.) less than the mean control in the experiment, and in variants 2 and 3 it was $0,85 \%$ (abs.) and $0,75 \%$ (abs.) respectively. showed to be low.

\section{Conclusions}

Analyzing the initial treatment method for cocoons, the results of the 2 (fumigation) and 3 (infrared rays) processing methods showed that the results were almost close to each other, and that the hot air treatment had a significant effect on the melting of the sericin in the shell. The fumigation method of anesthetizing the sponge and drying it in the shade retains the properties of the shell well, but the main drawback is that the release of chemicals retained in the cocoon during the drying of the cocoons has a negative impact on the health of workers. In variant 3 , complete drying in the shade by anesthetizing a live cocoon sponge under the influence of infrared light ensures good bending, evaporation and good rinsing during the rinsing process due to the well-preserved technological properties of sericin.

\section{Acknowledgment}

This research project IOT-2015-2-8-"Application of advanced, resource-saving technology of primary cocoon production" and OT-F4-14-"Preparation of cocoons for spinning and the creation of a theoretical basis for the production of raw silk" was carried out on the basis of financial support. The authors express their gratitude to the scientific team of the project, the heads and staff of the Silkworm Silk Factory of Kashkadarya region and Ortachirchik district of Tashkent region for the creation of raw cocoon materials and favourable conditions for this research during the spring and secondary cocoon production seasons. 


\section{References}

1. CM-4 of the Cabinet of Ministers of the Republic of Uzbekistan from January 5, 2006 of No. DP-3706 "About measures for stimulation of expansion of cooperation between large industrial enterprises and production and services on the basis of development of home-based work" -number decision

2. Resolution of the President of the Republic of Uzbekistan dated June 7, 2018 No RP3777 "'On the implementation of the program" Every family is an entrepreneur"

3. Resolution of the President of the Republic of Uzbekistan dated July 14, 2018 No RP3856 "On measures to improve and increase the efficiency of work to ensure employment"

4. Resolution of the President of the Republic of Uzbekistan dated May 20, 2020 No RP4720 "On additional measures to finance the program" Every family is an entrepreneur"

5. Resolution of the President of the Republic of Uzbekistan dated October 13, 2020 No RP-4862 "On additional measures to improve the system of entrepreneurship and development of entrepreneurship"

6. Resolution of the President of the Republic of Uzbekistan dated April 21, 2021 No RP5087 "On additional measures to improve the system of business support, further improve the business environment"

7. H. Alimova, A. Yu. Rakhimov, N. N. Nabidjanova, J. A. Akhmedov, Uzbekistan Textile Journal 4, 12 (2020)

8. K. R. Avazov, Izvestiya vysshix uchebnyx zavedeniy. Technology tekstilnoy promyshlennosti 371(5), 80-83 (2017)

9. K. Avazov, Journal of Fergana Polytechnic Institute 3, 107-110 (2016)

10. X. Alimova, Scientific and technical journal "Silk" 1, 6 (1996)

11. Kh. Alimova, K. R. Avazov, The problems of textiles 4, 15 (2016)

12. X. Jin, J. Zhang, W. Gao, J. Li, Textile research journal 15(3), 19 (2015)

13. K. Avazov, Scientific and technical journal "Textile Problems" 1, 97-100 (2008)

14. K. R. Avazov, European Applied Sciences 12, 10 (2015)

15. K. R. Avazov, X. D. Bastamkulova, Austrian Journal of Technical and Natural Sciences 1, 8 (2016)

16. Kh. Alimova, K. R. Avazov, D. Zakirova, N. Khakimov, International Journal of Advanced Research in Science, Engineering and Technology 5(12), 7 (2018) 